\title{
O ESTADO, A NAÇÃO E O ESTADO-NAÇÃO
}

\author{
THE STATE, THE NATION AND THE NATION-STATE
}

Deise Baumgratz ${ }^{1}$

RESUMO: O presente artigo está dividido em três partes, no primeiro momento expõe-se a teoria de formação de Estado de Engels, descrevendo como se deu a formação do Estado, vinculando principalmente a evolução da propriedade privada e, portanto, aos interesses do capital e das classes hegemônicas. Na sequência, através de análise bibliográfica explana-se sobre o processo de concepção da Nação, no sentido de identidade, reforçando não se tratar de um processo natural, mas arquitetado pelo Estado na tentativa de homogeneização e governabilidade da população, de forma romântica, levando populações inteiras a matar e morrer em defesa da nação. Por último ratifica-se como o Estado-nação se utiliza do poder simbólico, do monopólio legítimo da violência e de outros fatores para controle da nação.

Palavras-chaves: Estado; Nação; Identidade; Dominação.

ABSTRACT: The present article is divided in three parts, in the first moment the theory of State formation of Engels is exposed, describing how the formation of the State took place, linking mainly the evolution of the private property and, therefore, to the interests of the capital and of the hegemonic classes. Following, through a bibliographical analysis, it explores the process of conception of the Nation, in the sense of identity, reinforcing that it is not a natural process, but is designed by the State in an attempt to homogenize and govern the population, in a romantic way, leading entire populations to kill and die in defense of the nation. Finally, it ratifies how the nationstate uses the symbolic power, the legitimate monopoly of violence and other factors to control the nation.

Keywords: State; Nation; Identity; Domination.

\section{INTRODUÇÃO}

O artigo apresenta a origem e formação do Estado, vinculado aos interesses do capital e para regulação da luta de classes. O surgimento do nacionalismo, não como algo nato ao homem, mas criado por meio de tradições e símbolos que são incorporados e naturalizados pela população, analisando a função da indústria editorial e o impulso das línguas vulgares nesse processo. A dominação do Estado sob a nação, de fato percebe-se que o nacionalismo surge quando o domínio da igreja é ameaçado pelo iluminismo e racionalidade científica, para unificação das massas.

\footnotetext{
${ }^{1}$ Administradora, especialista em Relações Internacionais pela Universidade Federal da Integração Latino-americana (UNILA), mestranda do programa Interdisciplinar: Sociedade, Cultura e Fronteira da Universidade Estadual do Oeste do Paraná (UNIOESTE), pesquisadora do Laboratório de Pesquisa Fronteiras, Estado e Relações Sociais (LAFRONT). E-mail: deiseb_72@hotmail.com.
} 
Através de diversos mecanismos, o Estado exerce o controle da civilização. Por fim, apesar de ser habitual a organização por meio do Estado-nação, percebe-se o afloramento de movimentos etnonacionalista em uma resistência contra hegemônica.

Para compreensão da atuação Estado-nação moderno, decidiu-se por uma divisão metodológica dos conceitos, para isso o artigo está dividido em: O Estado, A Nação e O Estado Nação. No primeiro momento será abordada a questão da formação do Estado com auxílio de Friedrich Engels (1820-1895), filósofo alemão, marxista traz grandes contribuições em relação ao capital, propriedade privada, Estado e luta de classes. Essa conceptualização se dá no aspecto institucional do Estado, formado pelo interesse do capital e das classes dominantes.

Na seguinte parte, será apresentado debates em relação ao surgimento do termo nacionalismo e formação da nação, abrangendo questões sobre a origem da identidade. Na sequência será exposto como o Estado se utiliza de diversos elementos, dentre eles o nacionalismo, e do uso legítimo da violência e do poder simbólico para controlar e organizar a sociedade.

Para a segunda e terceira seção são utilizadas as contribuições de Max Weber (1864-1920), sociólogo alemão que versa sobre o capitalismo, dominação, burocracia e Estado, principalmente empregando sua obra: Economia e Sociedade: fundamentos da sociologia compreensiva (2012) originalmente publicado em 1913. Na discussão de identidade e nacionalismo serão utilizados Benedict Anderson (1936-2015), historiador com nacionalidade estadunidense, nascido na China de pais indonésios cujo muitos anos de vida passou na Europa; Eric Hobsbawn (1917-2012), historiador inglês, marxista e seu texto sobre a Invenção das Tradições e Pierre Félix Bourdieu (1930-2002), sociólogo francês, foi docente na École de Sociologie du Collège de France, o qual suas aulas nos três cursos dedicados ao Estado nos meses de dezembro de 1989-fevereiro de 1990 são mais tarde transcritas por seus alunos no livro On the State.

Os quatro últimos autores têm em comum a fase que desenvolveram suas teses, vivendo na Europa no período das grandes Guerras Mundiais, em um momento de plena expansão do capitalismo, das indústrias e de independência das Américas, além de vivenciar o declínio do poder da igreja no período iluminista.

O termo nação representa a coletividade de indivíduos de um mesmo território, delimitado e sob um único governo e apenas existe devido ao campo propício à sua expansão proporcionado pelo surgimento do Estado.

\section{O ESTADO}


A organização da civilização como a conhecemos atualmente não foi sempre deste modo, o Estado não é uma premissa da população e surgiu para o aparelhamento do capitalismo. Engels em 1884 em sua obra A Origem da Família, da Propriedade e do Estado propõe uma hipótese sobre a origem do Estado.

Inicialmente as sociedades eram divididas em gens, comunidades, onde o casamento era grupal, inclusive entre consanguíneos, sendo assim a descendência e hereditariedade era conformada pela mãe, as terras pertenciam a comunidade e o trabalho era coletivo, uma verdadeira comunidade comunista. Com o tempo, convencionou-se a proibição de relações sexuais entre consanguíneos, dando um passo a caminho do casamento monogâmico.

$\mathrm{O}$ aumento da população juntamente com a domesticação de animais originou o cultivo individual da terra ocasionando a produção de excedentes. Com isso, o homem deixou de produzir apenas para subsistência da gens, efetivando trocas com outros produtos. O desenvolvimento das forças produtivas e do domínio do ferro iniciaram uma nova etapa na organização social.

Com a propriedade privada, o homem dominava o trabalho, enquanto a mulher dominava a casa. A hereditariedade das posses já não podia ser materna, deveria ir aos filhos e, portanto, requeria-se a fidelidade e a união monogâmica. A família, portanto, desempenhou papel relevante nessa transformação. $\mathrm{O}$ aumento das trocas, evolução das forças produtivas requeria um organismo externo que organizasse as atividades comerciais e protegesse a população, com isso surge o Estado.

Em realidade, Engels relata que o Estado surge para controlar dentro de uma ordem estabelecida como normal, a luta entre as classes. Para alcançar este objetivo, juntamente com o Estado é instituída uma força pública, a força de polícia. Essa população, arruinada pelas guerras e saques são obrigadas a se colocar sob a proteção desse Estado, o que lhes custava caro. Para manter a força pública é cobrado dos cidadãos os impostos. Esse Estado passa também a negociar letras, títulos, contrair empréstimos e negociar na bolsa.

Resumindo: a riqueza passa a ser valorizada e respeitada como bem supremo e as antigas instituições da gens são pervertidas para justificar-se a aquisição de riquezas pelo roubo e pela violência. Faltava apenas uma coisa: uma instituição que não só assegurasse as novas riquezas individuais contra as tradições comunistas da constituição gentílica, que não só consagrasse a propriedade privada, antes tão pouco estimada, e fizesse dessa consagração santificadora o objetivo mais elevado da comunidade humana, mas também imprimisse o selo geral do reconhecimento da sociedade às novas formas de aquisição da propriedade, que se desenvolviam umas sobre as outras - a acumulação, portanto, cada vez mais acelerada, das riquezas - ; uma instituição que, em uma palavra, não só perpetuasse a nascente divisão da sociedade em classes, mas também o direito de a classe possuidora explorar a não-possuidora e o domínio da primeira sobre a segunda (Engels, 2009. p. 135). 
O que Engels fez em sua obra foi uma gênese da formação do Estado, os próximos autores trazidos trabalham com esse Estado já existente, aclarando como ele opera no período moderno, esses aspectos serão tratados com maior afinco na terceira seção deste artigo, mas para expandir o debate antes de entrar na conceptualização de nação expõe-se o resumo da ideia de Estado-nação moderno para Weber e Bourdieu.

O Estado para Weber (2009) é o ator fundamental para o sucesso do capitalismo. Ele descreve que em vários momentos as crenças foram impedimentos para o sucesso do capitalismo, pois tornavam o sistema muito volátil, as regras não eram fixas e por isso o capital não conseguia expandir de maneira vertiginosa. $\mathrm{O}$ avanço da ciência e da razão e a organização da sociedade através do Estado permitiu uma previsibilidade vantajosa ao sistema capitalista, que garantia aos empresários uma estabilidade e lhes dava a segurança necessária para fazerem investimentos. Em determinado momento relaciona o capitalismo, o Estado e a religião, demonstrando que a religião protestante está atrelada ao avanço e sucesso do capitalismo, em virtude dos princípios da referida religião estar atrelados ao trabalho árduo, a acumulação e predestinação como premissas para entrar em comunhão com Deus.

Ainda sobre o Estado, Bourdieu (1989) alega que esse não passa de uma ilusão bem fundada, como uma abstração, pois não existe o Estado, existem agentes e atos que incorporam instituições do Estado. O autor considera a importância da formação da identidade para a consolidação do Estado-nação. O Estado é um campo de poder, definido pela posse do monopólio legítimo da violência física e simbólica em um território e sob uma população definida.

O que fora descrito acima, refere-se a organização de Estado enquanto instituição política, que surge enquanto organização da sociedade para defesa do interesse da classe dominante, possibilitando o desenvolvimento do capitalismo. Esse Estado mantém o monopólio da força física e não pode ser visto como um indivíduo ou algo natural, mas um processo com uma origem e fundação. Esse Estado formado enquanto instituição se utiliza de meios para manipulação e coação da sociedade ou melhor da nação.

\section{A NAÇÃo}

A identidade nacional que é uma concepção natural hodierna, tem uma história e uma criação. Em qualquer lugar do mundo em que um indivíduo nascido no Brasil estiver será brasileiro, isso garante direitos e impõe limites. Apesar das mais gritantes diferenças culturais, sociais e econômicas dentro do território a nacionalidade é um símbolo capaz de unir todos. 
Justamente essa busca de homogeneidade das massas foi o que originou o nacionalismo, remetido ao período pós revolução francesa de plena expansão capitalista. Sua forma romântica, como o modelo alemão, prevê uma variedade de símbolos, estátuas, memoriais, representando heróis que lutaram e morreram pela liberdade do povo, esse herói é normalmente criado de forma abstrata possibilitando a identificação individual com a figura. Igualmente, cria-se a imagem de um inimigo comum do Estado e da segurança da população, apelando para emoções e sentimentos subjetivos.

Até final do século XVII as monarquias e dinastias eram a forma legítima de governo, se baseavam na religião, guerra e em casamentos para manutenção do poder, o advento do iluminismo visibilizou a ciência levando a decadência das monarquias e do poder da igreja sob a população. Durante o século XIX os países das Américas começaram a se tornar independentes, gerando um ambiente propício para a consolidação do Estado e nascimento do nacionalismo.

Benedict Anderson em seu livro Comunidades Imaginadas (1983) analisa a formação das nacionalidades e a define como uma comunidade política imaginada (p.14). Os brasileiros podem estar espalhados por qualquer parte de globo, mesmo assim vão se identificar com seu nacionalismo original. Um grupo de hip-hop negro, mesmo sem sair de seu território podem se remeter a uma identidade nacional africana, uma imagem criada de uma nação. Realça que é imaginada porque é sempre limitada e soberana, por menor que seja a nação seus membros nunca se conhecerão por completo, mesmo assim formam uma imagem de unidade comum, ou por maior que seja, ainda assim terão fronteiras e limites, ainda que permeáveis.

Talvez com exceção da gens primitiva referida no texto de Engels, tal afirmação é verídica. Anderson trata a nação em analogia a uma religião ao invés de uma ideologia, como muitos o fazem e descreve esse nacionalismo como criado, por meio da religião e de símbolos - como o túmulo vazio em praça pública, que emerge a figura de um herói de guerra que representa ao mesmo tempo o individual e o todo. "Estamos diante de um mundo em que a representação da realidade imaginada era irresistivelmente visual e auditiva" (ANDERSON, 1997. p.31). Os esportes nessa mesma perspectiva unem pessoas por um ideal comum, a ideia de um time nacional que todos defendem, vão aos estádios e se tornam um só.

Nesta mesma perspectiva Eric Hobsbawn expõe um texto sobre as tradições inventadas. O autor descreve a tentativa de se criar um nacionalismo através de duas estratégias:

pelo conceito de um inimigo secular nacional contra o qual o povo alemão havia definido sua identidade, lutando para obter a unidade como Estado; e pelo conceito de conquista ou supremacia cultural, política e militar, pelo qual a nação alemã, espalhada por grandes partes de outros países, principalmente na Europa central e oriental, podia reivindicar o direito de unir-se num Estado Maior alemão (1997. p.282). 
Tanto na Alemanha na década de 30 e 40 onde a população era nascida no país, quanto nos EUA onde a maioria da população era imigrante e, portanto, não tinham vínculo de nascimento no país, precisava-se criar tradições de união do povo. No primeiro observa-se um grande número de estátuas e monumentos espalhadas pelo país que representam imagens de heróis nacionais, no segundo os imigrantes foram incentivados a aceitar rituais que comemoravam a história da nação e absorveu-se os rituais coletivos dos imigrantes. Por outro lado, o sistema educacional foi transformado num aparelho de socialização política através da veneração da bandeira americana que da década de 1880 em diante tornou-se um ritual diário nas escolas rurais (HOBSBAWN, 1997).

O idioma representa um rol basal na formação de identidade, também assinala a força e poder das classes, sendo a língua imponente a língua da classe dominante. Em territórios colonizados, o idioma oficial é aquele do colonizador, estigmatizando e reforçando fronteiras entre os grupos sociais. $\mathrm{O}$ acesso à educação, a informação e consequentemente a participação política igualmente é limitada a alguns grupos.

Esse nacionalismo cunhado pelo Estado moderno para unificação das massas não considerou as diferentes etnias, idiomas e características dos grupos já existentes nos espaços, atendeu apenas aos interesses dos grupos dominantes, no sentido do capital. Michael Banton (1979), em a Ideia da Raça explica que os grupos de maior número não são necessariamente dominantes pois não tem a força exigida dentro do processo decisório e de formação de política.

Bourdieu traz a religião e a etnia como dois espaços parcialmente independentes dos outros capitais. Cada etnia poderia ser caracterizada pelas posições sociais dos seus membros e pela integração social destes (1989, p.136). Banton (1979), alega que a etnia e religião podem ser incorporadas pelo Estado quando interessa a ele, "Em algumas sociedades, é normal que qualquer cidadão tenha uma identidade étnica e nacional, mas, em outras, o ideal da cidadania comum é suposto de superar os particularismos étnicos e os sentimentos étnicos são mal vistos e pouco encorajados” (BANTON, 1979. p.166). Quando analisa as políticas e Estado e o nacionalismo dos EUA, percebe a ausência da consideração da raça negra na construção nacional. Na América-Latina movimento semelhante ocorreu com os indígenas e negros.

Primeiramente observando a colonização do território latino vê-se a imposição da cultura e tradição europeia frente a população originária. Quando estes países começam a se tornar independentes um idioma oficial é estabelecido, não considerando a maioria ou as etnias já existentes mas aquela dominante em relação ao poder do capital econômico.

Anderson destaca o papel do capitalismo editorial no período de independência e formação de identidade dos países colonizados, a consolidação de línguas vulgares e a decadência do latim 
facilitou a comunicação entre membros da sociedade. "Em suma, a decadência do latim exemplifica um vasto processo em que as comunidades sagradas, integradas pelas antigas línguas sagradas, gradualmente se fragmentavam, pluralizavam e territorializavam” (ANDERSON, 1979. p.27). A imprensa gráfica, a mídia, o aumento da produção de livros em línguas vernáculas e os jornais, escritos com certo romantismo, faziam com que as populações mais remotas se sentissem conectadas, as pessoas tinham a sensação de estarem informadas sobre tudo o que estava ocorrendo em outros espaços naquele momento.

Os romances eram escritos de forma a criar a imagem de uma comunidade, descrita de modo genérico, retratando na literatura um herói, como "nosso jovem", igualmente aos túmulos vazios e memoriais em praças públicas na Europa, criam a imagem de um jovem que pertence ao corpo coletivo dos leitores. (ANDERSON, 1979. p.41). Ainda hoje nota-se este poder da mídia, a falsa ideia de aldeia global, de todos sentirmos informados e conectados. Quando, com algumas exceções, a mídia é ferramenta de manipulação de massas para o desenvolvimento do capital e dos interesses hegemônicos.

Uma crítica feita a Benedict Anderson, é que o autor relata esse movimento de formação do nacionalismo como algo natural, quando na realidade não foi assim.

Um problema na tese de Anderson [...], é a sugestão de que o nacionalismo nas colônias e no Terceiro Mundo foi uma reação mais ou menos passiva, ou tomada de empréstimo, ao impacto europeu.[...] Embora as reações coloniais e póscoloniais na maioria dos casos tivessem assumido a forma de "revoluções passivas", elas também foram dialeticamente engendradas e filtradas pelas experiências de líderes e elites locais de diversas posições, cujas opiniões políticas não eram de modo algum unitárias e homogêneas (TAMBIAH, 1997).

Portanto apreende-se primeiramente a criação de um Estado que surge com o capitalismo para defesa do capital e dos interesses das classes. Em um segundo momento, podemos ver a formação da nação e da identidade através da criação de símbolos como a bandeira, os hinos nacionais, monumentos de guerras, esportes, uniformes escolares etc. como meio de unificação das massas. Essa incorporação de símbolos é o que leva populações inteiras a matar e morrer em nome de uma nação, ou de algo imaginado. Tais mecanismos veremos a seguir, são incorporados pelo Estado para legitimar seu poder e para influenciar e controlar a população.

\section{O ESTADO-NAÇÃO}

O Estado utiliza meios para governabilidade dessa nação criada. Para Weber a dominação se refere à possibilidade de se obter obediência de um determinado grupo, sendo assim, o Estado é uma "relação de dominação de homens sobre homens", na qual os dominados submetem-se à 
autoridade invocada pelos dominantes (Weber, 2012, p. 526). Para explicar o autor divide a autoridade legítima em três categorias: tradicional, carismática e burocrática.

Autoridade tradicional, como eram nas monarquias, refere-se a hereditariedade, "do costume sagrado por validade imemorável e pela disposição habitual de respeitá-lo" (WEBER, 2012, p.526). Autoridade carismática relaciona-se com as características do indivíduo que está no poder, dominação por suas qualidades heroicas ou proféticas. Por fim a autoridade burocrática vincula-se a legalidade, as normas racionalmente criadas e fixadas em estatutos e a disposição de obediência ao cumprimento destas normas. A obediência também está relacionada aos medos e expectativas do dominado em relação ao dominante.

Os indivíduos se organizam e abrolham o poder legítimo de dominação a um representante, que em momentos se deu na figura do príncipe, e depois em uma instituição, tal conceito se relaciona com o trazido por Hobbes, para ele:

Uma comunidade política pode dizer-se instituída, quando um grande número de homens põe-se de acordo, e pactua, entre si, que a maioria dará a qualquer homem, ou assembleia de homens, o direito de apresentar a pessoa de todos eles, isto é, de ser seu representante; cada um autorizará todas as ações e julgamentos daquele homem, ou daquela assembleia de homens, da mesma maneira como se fossem as ações e julgamentos dele mesmo (1974, p. 29).

Anderson e Hobsbawm trazem os símbolos, a religião, eventos e datas comemorativas nacionais como elementos de formação de uma identidade nacional. A nação é uma forma de delimitar o contingenciamento do poder de um governo sob uma determinada população, é estabelecer fronteiras inclusivas entre o "nós" e exclusivas para o "outro". Cria-se um sentimento de pertencimento que leva nações inteiras a matar e morrer em nome de um país. O hino nacional brasileiro expressa bem isso quando realça: "Verás que um filho teu não foge à luta, nem teme, quem te adora, a própria morte. Terra adorada" (ESTRADA, 1971).

A ideia de liberdade foi incorporada ao nacionalismo e protegido na manutenção da ordem pelo Estado, através de diversos mecanismos. No entanto, embora os processos interativos globais promovam efeitos homogeneizadores, são responsáveis por criar de diferenciações e antagonismos no interior das novas sociedades, os quais se manifestam na forma de conflitos étnicos (TAMBIAH, 1997).

A manutenção do poder do Estado se dá dentre outras maneiras pelo poder simbólico, relacionado com o prestígio, a fama, a reputação etc. O poder simbólico é a percepção e reconhecimento das espécies do capital como legítimo por um grupo ou um agente na estrutura existente (BOURDIEU, 1989. p.145), as divisões sociais e hierarquias existentes são a percepção e 
aceitação como tal, no entanto esta naturalização é produto de um esquema construído. Através do poder simbólico, o indivíduo exerce influência em um determinado tempo, sob um determinado campo de acordo com seu domínio de capital, seja econômico, cultural ou simbólico - habitus.

Habitus é o conjunto de experiências coletivas e acumulo de capital (cultural, econômico, social, simbólico) que o indivíduo internaliza, agindo em seu campo social de acordo com o resultado destes processos, no entanto os capitais tendem a uma hierarquia dominado pelo capital econômico. Esse habitus é relevante dentro de um espaço delimitado. Pode-se representar o "mundo social em forma de espaço" (BOURDIEU, 1989, p. 133), construído sob uma base de diferenciações e num conjunto de propriedades, que garante ao detentor destas características, força e poder de atuação neste espaço. Desenvolve- se o conceito de field - campo - relacionado ao espaço de atuação e influência deste habitus, o campo de forças é "um conjunto de relações de forças objetivas, imposto a todos os que entrem nesse campo" (BOURDIEU, 1989, p.134).

Os capitais têm diferentes forças dependendo do campo que atuam e garantem poder sobre este (num dado momento) e sobre o produto acumulado do trabalho. $\mathrm{O}$ ator vai deter um poder em um determinado campo em um momento específico dependendo do capital ou habitus que detém. Para exemplificar, o capital cultural (o mesmo vale para os outros) vai ser relevante dentro de um campo onde o capital cultural tem poder de influência (dentro de uma universidade por exemplo), determinante para posicionar o sujeito dentro do grupo, e pode não ter a mesma influência em outro (grupo familiar), no qual o capital cultural não seja tão relevante.

O poder simbólico é formidável ferramenta de dominação, sendo usado de tal maneira que seduz, persuade o indivíduo a reconhecê-lo e aceitá-lo. A escola, para Bourdieu é um dos instrumentos de poder simbólico do Estado que garante o habitus do ser social. Weber menciona que a cultura tem o mesmo papel da religião, e que as autoridades usam estes fatores para governar e influenciar, ou melhor, dominar a população.

É consenso entre Bourdieu e Weber o monopólio legítimo do uso da violência e força física pelo Estado. Para Weber o Estado é uma representação do poder de dominação dos povos mantida por meio da violência e da força física, o Estado-nação tem o monopólio do uso de tais ferramentas de coerção de forma legitimada pela população, já que esta abdica o seu uso para convivência em sociedade, tendo sua segurança garantida pelo Estado. Além disto, formulam leis para controlar a conduta da sociedade, para ele o Estado racional baseado em normas e em um sistema organizacional e não mais conexo a crenças ou superstições, é o único que permite o desenvolvimento e expansão do capitalismo moderno, pois, neste regime é possível prever as situações econômicas as regras não são flutuantes, permitindo negociações sólidas, existindo uma hierarquia e especialização do trabalho (WEBER, 2012). 
O Estado, é aquela comunidade humana que, dentro de determinado território (...) reclama para si (com êxito) o monopólio da coação física legítima, pois o específico da atualidade é que a todas as demais associações ou pessoas individuais somente se atribui o direito de exercer coação física na medida em que o Estado o permita (WEBER, 2012, p. 525-526).

Portanto, pode-se destacar das análises de Bourdieu que o indivíduo é a representação do acúmulo de suas experiências e de capitais, formando o habitus. Há uma hierarquia dentro das espécies de capitais, que faz com que o capital econômico exerça maior influência sobre os outros. O poder simbólico é utilizado pelo agente, e no que tange este artigo pelo Estado, para legitimar ações e organizações sociais. “O Estado é um princípio de produção, de representação legítima do mundo social" (BOURDIEU, 2014, p. 30).

Bourdieu faz uma crítica a teoria marxista, afirmando que ela não levanta o problema de existência do Estado, apenas definindo as funções que ele preenche, já que para os marxistas "o Estado não é um aparelho orientado para o bem comum, é um aparelho de coerção, de manutenção da ordem pública mas em proveito dos dominantes” (2014, p. 32). Apresenta uma analogia entre o Estado e religião ambos cumprindo funções de conservação social e de condições para acumulação de capital.

Em outras palavras, para resumir antecipadamente o que vou expor a vocês, diria que Estado é o nome que damos aos princípios ocultos, invisíveis - para designar uma espécie de deus absconditus - da ordem social, e ao mesmo tempo da dominação tanto física como simbólica assim como da violência física e simbólica (2014, p. 34).

Para o autor o Estado é uma ilusão formada e legitimada pela crença e consenso coletivo, alerta para o risco de usar o termo como sujeito. Se partir da realidade, analisando alguns fenômenos como: identidade, diploma, relógios, calendários etc. observa-se que o Estado não é natural, tem uma origem e uma criação. O Estado seria uma espécie de organizador da ordem social e acima de tudo formador e mantenedor das classes sociais. A identidade do indivíduo é na verdade uma identidade legítima imposta pelo Estado (BOURDIEU, 2014). Os atos do Estado só existem devido a crença e a legitimidade dada a eles, por exemplo um indivíduo só se revolta contra uma estrutura social porque aceita sua existência, o estudante reclama da nota pois aceita sua estrutura de avaliação.

Pode-se observar em momentos distintos autores que trazem contribuições relevantes para o conhecimento da fundação e consolidação do Estado. Primeiramente ele surge em virtude do desenvolvimento da propriedade privada, para organização das lutas de classes em defesa do capital. A formação do nacionalismo, traz a ideia de unidade que torna mais fácil a governabilidade 
desse povo. Juntamente com o poder legítimo da força e da violência, o Estado se utiliza das formas de dominação para controlar a população e fortalecer o capitalismo.

\section{CONSIDERAÇÕES}

O Estado moderno foi o que permitiu a criação do nacionalismo. A religião costumava controlar o homem pelo poder divino do mesmo modo que crenças e normas da igreja. $\mathrm{O}$ iluminismo trouxe ascensão a ciência e a decadência do poder da igreja. Nesse contexto desenvolve-se o nacionalismo orgânico, com o objetivo de unificar as massas para o controle do Estado. Para isso diversos mecanismos são utilizados, tais como estátuas, remetendo a memória de heróis nacionais que sacrificaram suas vidas pela liberdade dos povos, bandeiras, hinos, além da criação da imagem de inimigos para à segurança daquela população.

No entanto essa formação nacional desconsidera as diferentes etnias existentes no território, os idiomas e culturas locais. Um único idioma é estabelecido como oficial, descartando e reforçando desigualdades entre as classes sociais.

Os autores não explicam como hoje, dentro do mundo globalizado poderia existir um sistema de organização social que não seja o Estado. Apesar de não ser nato do homem o Estado foi naturalizado de tal forma pela população tornando inviável a imaginação de outro arranjo. Principalmente por estarmos alocados em um sistema capitalista que demanda a figura de uma entidade superior, reguladora e defensora dos interesses do capital econômico, tendendo ao fortalecimento de tal representação.

O Estado, portanto, utiliza distintas ferramentas para coesão social. O nacionalismo foi um sentimento de pertencimento que emergiu e foi fortalecido em determinadas circunstâncias. Apelando aos sentimentos individuais, o Estado incorpora elementos que geram a sensação de incumbência a um grupo e distanciamento de outro, ressaltando símbolos como bandeira, hinos, esportes nacionais para atingir seus objetivos. Para Benedict Anderson o nacionalismo teria surgido no novo mundo e depois levado para a Europa, essa teoria não é consenso, mas sua análise de formação de identidade nacional nessas colônias independentes através do capitalismo editorial tem grande fundamentação.

Após consolidado o nacionalismo, o Estado passa a governar essa nação, ratificando sempre os interesses das classes dominantes, verifica-se isso pelas políticas nacionais, conforme trazido por Michael Banton (1979), as minorias - no sentido do capital - raramente são atendidas nos programas estatais. Para dominar a população, o Estado conta com o monopólio legítimo da força 
física e da violência. Esse monopólio lhe foi dado pela própria população e por isso referida instituição seria apenas uma ilusão, dada que existe apenas devido a crença da população nela.

O poder simbólico representa parte fundamental da manipulação estatal. Ritos, calendários, relógios e titulações são alguns dos elementos trazidos por Bourdieu como poder simbólico. Ferramentas que fazem parte de um processo construído, mas naturalizado na sociedade e que garante poder ao detentor dos diferentes capitais.

É errôneo dizer que esse Estado não encontrou resistência. Aqueles grupos étnicos que não são considerados dentro da formulação de políticas estatais se organizam de forma a contraporem o poder dominante. Criam símbolos próprios que os identificam enquanto unidade. Exemplo dos negros nos EUA ou do movimento dos sem terras no Brasil. Banton (1979), alerta para o fato de grupos estarem preservando a etnicidade acima do nacionalismo, exaltando o sentimento de pertencimento a uma sociedade internacional e buscando o reconhecimento dos seus membros dentro do Estado-nação.

Na mesma linha, Tambiah (1997) supõe uma transição de um período atual do governo nacionalista para um governo etnonacionalista, relacionado "com a formulação de respostas e resistências regionais ou subnacionais ao que é percebido como um Estado hegemônico excessivamente centralizado e com o desejo de construir formações sociopolíticas regionais e locais autônomas".

\section{BIBLIOGRAFIA}

ANDERSON, B. Comunidades Imaginadas. São Paulo: Companhia das Letras, 2008.

BANTON, Michael. A idéia de raça. Lisboa: Edições 70, São Paulo: Martins fontes, 1979 [1977]. (VIII, "Etnogênese", p. 153-173).

BIANCHI, Alvaro. O conceito de Estado em Max Weber. São Paulo: Lua Nova, 2014. Disponível em:<http://www.scielo.br/pdf/ln/ng2/a04n92.pdf $>$ acesso em: 20 de Jul. 2017.

BOURDIEU, Pierre. A identidade e a representação. Elementos para uma reflexão crítica sobre a idéia de região". In: O poder simbólico. Lisboa: DIFEL, Rio de Janeiro: Bertrand Brasil, 1989. p. 107-132

BOURDIEU, Pierre. Sobre o Estado: Cursos no Collège de France (1989 -92). [edição estabelecida por Patrick Champagne...[et al.]]; tradução Rosa Freire d'Aguiar - 1aed. — São Paulo : Companhia das Letras, 2014.

ELIAS, Norbert. "Uma digressão sobre o nacionalismo. Os Alemães: A luta pelo poder e a evolução do habitus nos séculos XIX e XX. Rio de Janeiro, Jorge Zahar Editor, 1997. pg. 119158.

ENGELS, Friedrich. A Origem da Família, da Propriedade Privada e do Estado. São Paulo: Escala, 2009. $3^{\circ}$ ed.

ESTRADA, Joaquim Osório Duque. Hino Nacional. Brasil, 1971. 
HOBBES, Thomas. Leviatã ou matéria, forma e poder de um Estado eclesiástico e civil. Coleção Os pensadores, vol. XIV. Tradução João Paulo Monteiro e Maria Beatriz Nizza da Silva. São Paulo: Abril cultural, 1974.

HOBSBAWN., E. J. Introdução e A produção em massa de tradições. In HOBSBAWN, E. J. E RANGER, T. A invenção das tradições. Rio de Janeiro, Paz e Terra, 1997.

WEBER, Max. Economia e Sociedade: fundamentos da sociologia compreensiva; trad. de Regis Barbosa e Karen E. Barbosa - 4 ed. - Brasília: Universidade de Brasília, 2012. Vol. 2.

TAMBIAH, Stanley J. (1997), "Conflito etnonacionalista e violência coletiva no sul da Ásia". Revista Brasileira de Ciências Sociais, 12, 34: 5-24 